\title{
Truar skilnadene i tilvisingsratar målet om likeverdige helsetenester?
}

\begin{abstract}
Samandrag
Bakgrunn. Sogn og Fjordane fylke har i landsmålestokk, og serleg i høve til dei andre fylka i Helse Vest, hatt eit høgt forbruk av spesialisthelsetenester. Utover det at fylket har to små lokalsjukehus, har lite vore kjent som kunne forklare det høge forbruket, og serskilt ikkje om det eksisterer kontrastar i forbruk mellom kommunane i fylket.
\end{abstract}

Materiale og metode. Med utgangspunkt i data frå Norsk pasientregister og journalsystemet DIPS for 2009 har vi samanlikna alders- og kjønnsjusterte forbruksratar på kommunenivå, saman med ujusterte tilvisingsratar til spesialisthelsetenesta på kommune- og enkeltlegenivå.

Resultat. Det var store skilnader i forbruk mellom kommunane både i kontaktratar og DRG-poeng. Skilnaden mellom kommunen med høgaste og lågaste forbruk var om lag 90 DRGpoeng per 1000 innbyggjarar. Kommunen med det høgaste forbruket brukar 36 DRG-poeng per 1000 innbyggjarar $\mathrm{i}$ året meir enn gjennomsnittet for Sogn og Fjordane. Ei nøyare samanlikning av tre kommunar med ulikt forbruk viser store og samanfallande skilnader i tilvisingsratar mellom kommunane og mellom enkeltlegar.

Tolking. Det høge og sprikande kommunale forbruket av spesialisthelsetenester i Sogn og Fjordane ser ut til å ha samanheng med tilsvarande høge og enno meir sprikande tilvisingsratar frå primærlegar i dei same kommunane.

\section{Olav Helge Førde}

olav.helge.forde@uit.no

Institutt for samfunnsmedisin

Universitetet i Troms $\emptyset$

og

Senter for klinisk dokumentasjon og evaluering Universitetssykehuset Nord-Norge

\section{Hans Johan Breidablik}

Helse Førde HF

Petter Øgar*

Fylkesmannen i Sogn og Fjordane Leikanger

* Noverande adresse:

Helse- og omsorgsdepartementet

Helse- og omsorgsdepartementet skriv i sitt høyringsnotat i samband med framlegget til ny kommunal helse- og omsorgslov at likeverdige tilbod om helsetenester er eit overordna mål, saman med målet om dempa vekst i bruk av sjukehustenester (1). I debatten omkring samhandlingsreforma har det vore hevda at ein betydeleg del av sjukehusinnleggingane er «unødvendige» og at fastlegane sin portvaktfunksjon inn til spesialisthelsetenesta ikkje fungerer optimalt. I seinare tid har ein fokusert på skilnader både i behandling og prioritering av enkelttilstandar innanfor spesialisthelsetenesta, noko som mellom anna har resultert i ei prioriteringsforskrift og utarbeiding av rettleiarar for prioritering innanfor dei fleste fagområda i spesialisthelsetenesta (2).

Sogn og Fjordane har eit høgt forbruk av spesialisthelsetenester med $12 \%$ fleire innleggingar og $23 \%$ fleire polikliniske konsultasjonar per 1000 innbyggjarar enn landsgjennomsnittet i 2009 (3). Dette trass i at fylket har klart lågare alderskorrigert total dødelegheit enn landsgjennomsnittet (4). Forventa levealder i fylket $(78,2$ år for menn, 83,5 år for kvinner i 2006) er også klart høgare enn landsgjennomsnittet (76,9 for menn og 81,9 for kvinner i 2006). I kontrast til eit høgt forbruk av spesialisthelsetenester finn vi òg at uttaket av uførepensjon, arbeidsløysetrygd og sosialhjelp er klart under landsgjennomsnittet i dette fylket (5).

Med dette bakteppet har vi ønskt å sjå på i kva grad det er skilnader mellom kommunar i Sogn og Fjordane i forbruk av spesialisthelsetenester. I tillegg ville vi sjå på kontrastar i tilvisingsratar for enkeltlegar i dei same kommunane. Til dette har vi valt ut tre perifere kommunar (A, B og C), som har ein del fellestrekk.
Målet med studien er å gjennom tilgjengelege kjelder beskrive og forklare variasjonane $\mathrm{i}$ forbruket av spesialisthelsetenester $\mathrm{i}$ kommunane i Sogn og Fjordane.

\section{Materiale og metode}

Tal for opphald og forbruk av spesialisthelsetenester er henta frå Norsk pasientregister. Forbruket omfattar alle behandlingsstader i Noreg. Forbruksratane er gjevne per 1000 innbyggjarar og er direkte alders- og kjønnsstandardisert med heile Noreg som referansepopulasjon.

Tilvisingsratane er henta ved eit datauttrekk frå Helse Førde av alle elektive tilvisingar som er vurdert og sett på venteliste $\mathrm{i}$ perioden, og der kontrollar og øyeblikkeleg hjelp er ekskludert. Avviste tilvisingar er heller ikkje med. For kvar tilvising blei det så gjort eit oppslag mot det pasientadministrative systemet, DIPS, for å hente rekvirentnamn og rekvirenten sin organisasjon. Deretter blei tilvisingane summert på rekvirent og fagområde. Uttrekket omfattar elektive primærtilvisingar samla til alle typar opphald, og er i tillegg fordelt på fire utvalde fagområde. Det er ikkje gjort uttrekk av pasientidentifiserbare opplysningar. Ratane er gjevne per 1000 pasientar på fastlegelista til einskildlegane. I tillegg er dei høgaste ratane av tilvisingar som førekjem i fylket tekne ut for samanlikning. Storleiken på listene er henta frå NAV.

Med omsyn til kontaktratar og tilvisingar har vi valt å samanlikne tre utkantkommunar med ulikt forbruk av spesialisthelsetenester. Dei har alle spreidd bumønster, lang reiseveg til sjukehus og rimeleg stabil primærhelseteneste. Alle desse kommunane har høg og lik prosent gamle i befolkninga ( $7 \%$

\section{Hovudbodskap}

- Trass i ein stadig aukande etterspurnad etter spesialisthelsetenester har lite vore gjort for å kartlegge årsakene til etterspurnadsveksten

- Nasjonale mål om likeverdige helsetenester har ikkje vore følgt opp med dokumentasjon på at dette er oppfylt

- Våre funn tyder på at målet langt frå er realisert på kommunenivå

- Høgt forbruk på kommunenivå kan sporast tilbake til høge tilvisingsratar frå enkeltlegar i dei same kommunane 
Tabell 1 Alders- og kjønnsstandardiserte opphaldsratar per 1000 innbyggjarar lomfattar behandling i alle regionar og både offentlege og private tilbydarar) fordelt på elektive og øyeblikkeleg hjelp. Tala er for døgnopphald og poliklinikk i tre utvalde kommunar i Sogn og Fjordane i 2009 (A-C). Ratar for Helse-Førde og Helse Vest er tekne med for samanlikning

\begin{tabular}{lcccc} 
& \multicolumn{3}{c}{ Døgnopphald } \\
Kolektive & $\emptyset$-hjelp & Totalt & Poliklinikk \\
Kommune A & 79,4 & 138,0 & 217,4 & 1188,9 \\
Kommune B & 60,5 & 107,6 & 168,1 & 882,2 \\
Kommune C & 60,5 & 119,3 & 179,8 & 633,5 \\
Helse Førde & 60,4 & 120,9 & 181,3 & 1079,8 \\
Helse Vest & 45,6 & 123,4 & 169,0 & 813,1
\end{tabular}

over 80 år), lik institusjonsdekning for personar over $80(19-21 \%)$ og svært lik primærlegedekning (10-12 legar per 10000 innbyggjarar). To er kystkommunar og ein er innlandskommune Kommunane er også etter måten samanliknbare med omsyn til kommuneprofilar (5), og serleg med omsyn til demografi og dødelegheit.

\section{Resultat}

Data frå Norsk pasientregister

Målt som forbruk av DRG-poeng i 2009 ligg bruk av spesialisthelsetenester i Helse Førdeområdet, som er identisk med Sogn og Fjordane fylke, over gjennomsnittet i Helse Vest, men under gjennomsnittet i Noreg (fig 1). Kontrastane mellom kommunane i Helse
Førde-området er markert, og skilnaden mellom kommunen med høgaste og lågaste forbruk er i 2009 om lag 90 DRG-poeng per 1000 innbyggjarar. Kommunen med det høgaste forbruket brukar $36 \mathrm{DRG}$-poeng per 1000 innbyggjarar i året meir enn gjennomsnittet for Helse Førde. Eit DRG-poeng tilsvarar om lag 36000 kroner.

Tabell 1 viser at i Helse Førde er det serleg samla døgnopphaldsratar som ligg over region- og landsgjennomsnittet. I all hovudsak er årsaka eit høgt forbruk av elektive døgnopphald. Også med omsyn til poliklinikkonsultasjonar ligg Helse Førde høgt. Kontrastane mellom dei tre utvalde kommunane er enno meir markert. Kommunen med det høgaste forbruket ligg godt over gjennom- snittet for Helse Førde både for elektive opphald og for øyeblikkeleg hjelp-opphald. Poliklinikkratane for denne kommunen er nesten dobbelt så høge som i kommunen med det lågaste forbruket av poliklinikk.

Ratar for elektive primærtilvisingar samla i 2009 til Helse Førde frå enkeltlegar i dei tre utvalde kommunane er vist i figur 2. Som ein ser, er det eit klart mønster der kommune A ligg høgt, kommune $\mathrm{C}$ ligg lavt (fordi lege $\mathrm{C}-1$ ligg svært lavt) og kommune $\mathrm{B}$ ligg i mellomsjiktet. Det er også markerte skilnader mellom enkeltlegar innan dei same kommunane. Lågaste tilvisingsrate finn vi hjå lege 1 i kommune $\mathrm{C}$, med 57 per 1000 listepasientar, og høgast hjå lege 4 i kommune $\mathrm{A}$, med 293. Den høgaste raten ein finn i fylket er likevel betydeleg høgare, 373, altså ein skilnad med ein faktor på omkring 6,5 til lege $\mathrm{C}-1$. I figur 3 er tilvisingsratane for dei fire fagområda ortopedi, urologi, kardiologi og psykisk helsevern for vaksne sett opp. Ratane for tilvisingar til dei einskilde fagområda varierer enno meir innbyrdes enn totalratane.

\section{Diskusjon \\ Hovudfunn}

Vi har i dette materialet påvist store skilnader i forbruket av spesialisthelsetenester mellom geografiske område innafor eit helseføretak som tradisjonelt har hatt eit høgt forbruk. Kommunen med det høgaste forbruket ligg langt over både gjennomsnittet og saman-

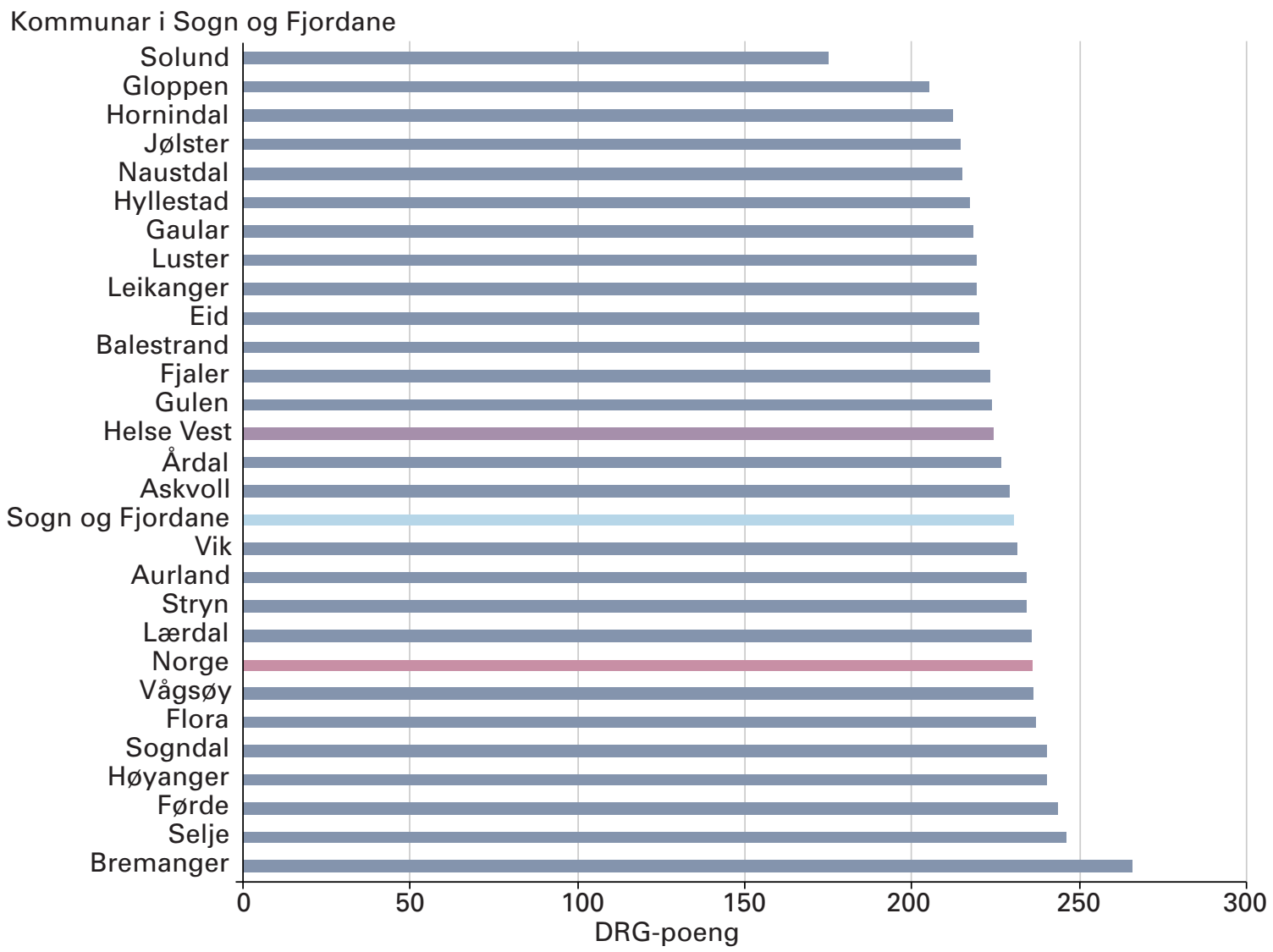

Figur 1 Alders- og kjønnsstandardisert spesialisthelsetenesteforbruk målt som DRG-poeng/1 000 innbyggjarar i kommunane i Sogn og Fjordane i 2009 , samanlikna med landsgjennomsnittet og med Helse Vest 


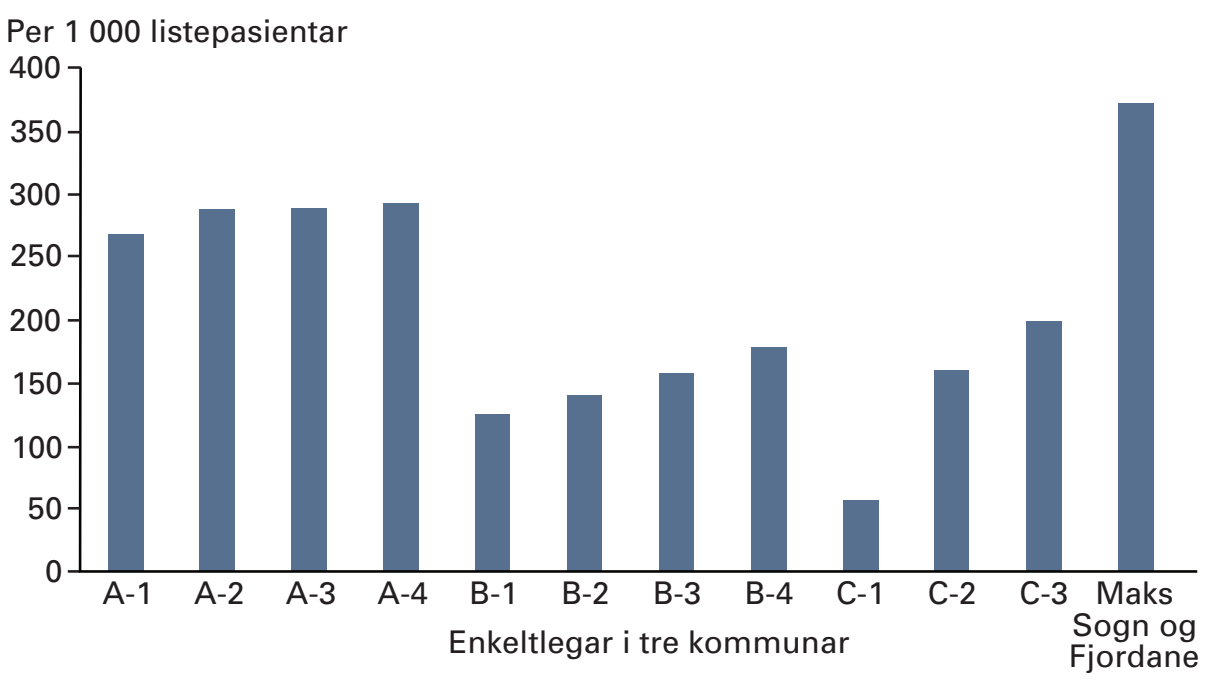

Figur 2 Samla rate av elektive tilvisingar (per 1000 listepasientar) for enkeltlegar i de tre kommunane A, B og C og maksimumsrate for enkeltlegar i Sogn og Fjordane i 2009 (Maks Sogn og Fjordane)

liknbare kommunar både med omsyn til kontaktratar og tilvisingar. Det høge forbruket ser ut til å ha samanheng med eit gjennomgåande høgt tal for tilvisingar frå enkeltlegar i denne kommunen. Variasjonane i tilvisingsratar frå enkeltlegar er svært store både samla og med omsyn til fagområde.

\section{Datakvalitet og feilkjelder}

Vi har valt å bruke data for eit år frå tre relativt små kommunar. Det kan gje opphav til tilfeldige variasjonar. Kontrastane i kontaktratar har på den andre sida vore svært konstante over fleire år, og vi valde difor å bruke det siste året der tal er tilgjengelege.

Datakvaliteten i Norsk pasientregister kan vere varierande, men data som er knytt til det økonomiske oppgjerssystemet (DRGforbruk og døgnopphald) er vurdert å ha etter måten god kvalitet. For poliklinikkonsulta- sjonar som i 2009 ikkje er inkludert i DRGoppgjeret, er materialet ikkje like komplett. Det gjeld serleg konsultasjonar hjå privatpraktiserande spesialistar. Dette spelar ei rolle for samanlikninga mellom Helse Førde, Helse Vest og heile landet, men har truleg mindre effekt for poliklinikkratane i dei tre enkeltkommunane som ikkje har privatpraktiserande spesialistar i nærområdet.

For tilvisingsratar som er basert på uttrekk frå DIPS, er datakvaliteten meir ukjent. Det gjeld serleg på tvers av helseføretak. Ettersom vårt materiale $\mathrm{i}$ all hovudsak er basert på uttrekk frå eitt føretak, Helse Førde, er det såleis svært lite truleg at dei markerte kontrastane som er påvist, kan forklarast med feil i datamaterialet. Grunna geografisk nærleik til Bergens-området er det truleg ein viss lekkasje av tilvisingar dit frå kommune $\mathrm{C}$. Storleiken på denne lekkasjen vil gje ei

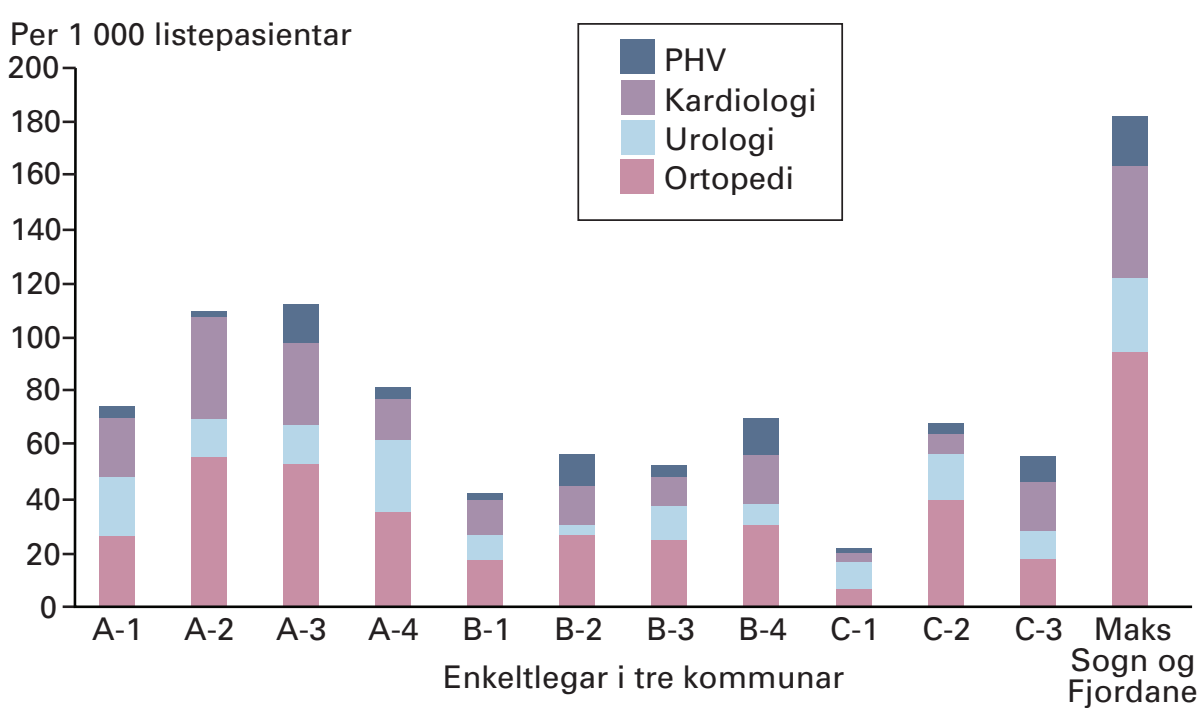

Figur 3 Elektive tilvisingsratar (per 1000 listepasientar) fordelt på fire fagområde i 2009 for enkeltlegar i dei tre kommunane A, B og C og maksimumsrate for einskildlegar i fylket (Maks Sogn og Fjordane). PHV = Psykisk helsevern for vaksne. Samla rate er gjeve i figur 2 mindre utjamning mellom kommunane, men truar ikkje våre hovudkonklusjonar. Diverre hadde vi ikkje tilgang på alders- og kjønnssamansettinga av fastlegelistene, men heller ikkje den manglande alders- og kjønnsstandardiseringa av tilvisingsratane kan forklare skilnadene. Slik justering for kontrastar i tilvisingsratar har vist seg å ha marginal effekt på skilnadene (6).

Fastlegeordninga er basert på ansvaret for eit utval av befolkninga i den aktuelle kommunen i form av ei fastlegeliste av ulik lengde. Listelengdene i Sogn og Fjordane er gjennomgåande låge: få har meir enn 1000 innbyggjarar på listene sine. Sidan det er pasientane sjølve/føresette som vel fastlege, er det truleg at desse utvala ikkje blir like korkje i alders- eller kjønnssamansetting. På same måte vil nok pasientar med kroniske lidingar kunne fordele seg ulikt mellom listene. Drift av pasientar mellom listene ved at pasientar oppsøkjer andre fastlegar enn sin eigen for å få tilvisingar, eller at enkelte fastlegar har utvida opningstider i eigen praksis, vil også kunne verke inn på tilvisingsratane. Variasjonane er likevel for store til at det er rimeleg grunn til at behovet for spesialisthelsetenester i befolkninga skulle variere så mykje. Det er difor truleg at det dannar seg lokale «tilvisingskulturar» knytte til kommunane, men også hjå den einskilde legen. Resultatet tyder difor på at den såkalla portvaktfunksjonen hjå fastlegane blir praktisert svært ulikt, og at det får følgjer for tilgangen til, og forbruket av, spesialisthelsetenester for dei populasjonane dei har ansvaret for.

\section{Nasjonale mål og forbrukskontrastar}

Overordna mål om lik tilgang til og forbruk av spesialisthelsetenester er ikkje oppfylt for dei geografiske områda vi har undersøkt. Skilnadene er rett nok mindre når vi brukar DRG-poeng som samanlikningsgrunnlag. Det kan forklarast ved at DRG-samanlikningane tek omsyn til pasienttyngde, eller forenkla: ressursforbruket knytt til behandlinga av enkeltpasientar. Sjølv om skilnadene basert på DRG er mindre, representerer likevel forbrukskontrasten mellom den kommunen i Sogn og Fjordane som brukar mest og den som brukar minst ein sum på om lag 3,5 millionar kroner per 1000 innbyggjarar per år.

Når kontaktraten er meir sprikande, kjem det truleg av at kommunane med høgt forbruk sender fleire «lette» pasientar til spesialisthelsetenesta enn kommunane med lågt forbruk. Helse Førde, som er kjent for eit høgt forbruk, får som føretak fleire slike pasientar enn resten av Helse Vest og landet, men justert for pasienttyngde gjennom DRG-systemet ligg føretaket under landsgjennomsnittet.

Sett opp mot høgt flagga nasjonale mål om likskap i tilgangen til og forbruket av helsetenester er det påfallande at data frå spesialisthelsetenesta ikkje er meir brukt til à samanlikne populasjonar og geografiske område. Samdata samanliknar rett nok kost- 
nader per innbyggjar på regionnivå (3), men samanlikningar av kontaktratar og forbruk mellom mindre populasjonar justert for alders- og kjønnssamansetting er sjeldne. Internasjonalt er slike studiar av «small area variation» langt meir vanlege, serleg med Wennberg-gruppa i USA (7). Kontrastane som er avdekt i denne artikkelen viser at det er på høg tid at både helsepolitikarar og spesialisthelsetenesta tek ulikskapane på alvor.

Forklaringa på ulikskapane ligg ikkje i dagen. Utover alders- og kjønnssamansetting er det naturleg å leite etter skilnader morbiditet og mortalitet, men korkje i krefteller dødelegheitsregisteret finn vi kommunekontrastar som er parallelle til dei vi finn for forbruket av spesialisthelsetenester (4). Dei høge kontaktratane for Sogn og Fjordane, som ligg i noregstoppen med omsyn til leveutsikter (4), er i denne samanhengen eit paradoks.

Tilvisingsratar, tilbod og medisinsk skjønn I staden for å leite etter kontrastar i helseindikatorar er det meir naturleg å leite etter årsakene $\mathrm{i}$ helsetenestestrukturen og i medisinsk skjønn og praksis.

Dei fylka som tradisjonelt har hatt høgt forbruk, Sogn og Fjordane, Nordland og Finnmark, har alle mange små lokalsjukehus. Det kan forklare noko av skilnaden på fylkesnivå, men ikkje dei vesentleg større kontrastane innanfor Sogn og Fjordane.

Det er meir naturleg å leite etter forklaringar knytt til kommunane og kjenneteikn ved primærhelsetenesta. Det kan sjølvsagt finnast andre faktorar som spelar inn, som næringsstruktur, sysselsetting, omsorgstenestetilbodet og så bortetter, men dei kan neppe forklare dei massive kontrastane som er påvist. Langt meir sannsynleg er praksisskilnader mellom primærlegane. Vi veit frå internasjonal litteratur at tilgang til tenester og skilnader i medisinsk skjønn er dei viktigaste prediktorane for forbrukskontrastar i helsetenester (7).

Store kontrastar i tilvisingsratar mellom primærlegar genererer ikkje berre uakseptable skilnader i tilgang til og forbruk av tenestene. Høge tilvisingsratar skapar auka etterspurnad og kostnader, samtidig som det gjev køar, ventetid og fristbrot, noko det er sterkt politisk fokus på. Vi kan sjølvsagt ikkje seie noko om kva som er det optimale tilvisingsnivået. Det er ikkje utelukka at dei legane som tilviser minst, underforbrukar tenester og at det kan vere til skade for pasientane. På den andre sida er det lite som talar for store helsetap knytt til for streng portvaktfunksjon, snarare er overforbruk av tenester etter kvart vorte eit problem (8). Ei norsk undersøking tyder på at fastlegereforma har gjort portvaktfunksjonen vanskelegare (9). Det har elles frå vårt land vore påfallande lite forsking knytt til kontrastar i tilvisingsratar. Stort sett har forskinga dreidd seg om kvaliteten på tilvisingar (10) eller tilvisingar til bestemte fagområde (11). Elles i Europa er det eit rikhaldig tilfang av slik litteratur $(6,12,13)$.

Ei anna aktuell utfordring ved store praksisskilnader mellom primærlegar er den komande samhandlingsreforma. Små kommunar med høgt forbruk som ikkje kan forklarast med demografi og auka sjukelegheit, vil få store problem med medfinansiering av spesialisthelsetenestene. Så langt er det heller ikkje lansert framlegg om truverdige styringsreiskapar for kommunane i høve til fagleg primærlegepraksis. Sjølv om våre data ikkje direkte speglar kvalitetsdimensjonen, er den sprikande tilvisingspraksisen urovekkjande også i eit kvalitetsperspektiv. Det å endre tilvisingspraksis ser heller ikkje ut til å vere noka enkel oppgåve (14).

\section{Konklusjon}

Vår konklusjon på funna i denne artikkelen er at spesialisthelsetenesta ikkje lenger kan sjå bort frå dei faktorane som skapar etterspørselsveksten, køane og underskota. Dei må stille krav til måten dei blir brukt på, og storsamfunnet må kunne stille og implementere rasjonelle, faglege krav, som nok i ein viss mon vil innskrenke den enkelte primærlegen sin faglege autonomi, men som er nødvendige for å utjamne dei uakseptable skilnadene i tilgangen til det viktige velferdsområdet som helsetenester er.

\section{Olav Helge Førde (f. 1946)}

er professor ved Institutt for samfunnsmedisin, Universitetet i Troms $\varnothing$. Han har fagleg bakgrunn i hjerte-kar-epidemiologi og helsetenesteforskning og er tidlegare styreleiar i Helse Nord.

Ingen oppgitte interessekonflikter.

\section{Hans-Johan Breidablik (f. 1954)}

er spesialist i øre-nese-halssykdommer, i allmennmedisin og i samfunnsmedisin. Han er fagdirektør i Helse Førde HF og stipendiat ved Institutt for samfunnsmedisinske fag. Universitetet i Bergen.

Ingen oppgitte interessekonflikter.

\section{Petter Øgar (f. 1953)}

er spesialist i samfunnsmedisin. Han har i mange år vore kommunelege i Hornindal og fylkeslege i Sogn og Fjordane. Nyleg vart han ekspedisjonssjef i Helse- og omsorgsdepartementet.

Ingen oppgitte interessekonflikter.

\section{Litteratur}

1. Fremtidens helsetjeneste: trygghet for alle. Sammendrag av høringsgrunnlag for Nasjonal helseog omsorgsplan (2011-2015). Oslo: Helse- og omsorgsdepartementet, 2010.
2. Helsedirektoratet. Prioriteringsveiledere. www.helsedirektoratet.no/prioriteringer helsetjenesten/publikasjoner (20.7.2011).

3. Samdata spesialisthelsetjenesten 2009. Rapport IS-0293 Oslo: Helsedirektoratet, 2010.

4. Helsedirektoratet. Kommunehelseprofiler. www. helsedirektoratet.no/kommunehelseprofiler (24.2.2009).

5. Norgeshelsa. Forventet levealder (2000-2005). Oslo: Nasjonalt folkehelseinstitutt, 2010

6. O'Donnell CA. Variation in GP referral rates: what can we learn from the literature? Fam Pract 2000 17: $462-71$

7. The Dartmouth atlas of health care. www.dartmouthatlas.org (8.3.2011).

8. Lee SB. Overtreated. Why too much medicine is making us sicker and poorer. New York, NY Bloomsbury, 2007.

9. Carlsen B, Norheim OF. Introduction of the patient-list system in general practice. Changes in Norwegian physicians' perception of their gate keeper role. Scand J Prim Health Care 2003; 21: 209-13.

10. Lønning KJ, Kongshavn T, Husebye E. Kvaliteten på henvisninger fra fastleger til medisinsk poliklinikk. Tidsskr Nor Legeforen 2009; 129: 1868-9.

11. Albretsen C, Hansen OA, Tingvoll SH et al. Tilvising til nevrolog i Troms og Finnmark. Tidsskr Nor Lægeforen 2006; 126: 3104-5.

12. Christensen B, Sørensen HT, Mabeck CE. Differences in referral rates from general practice. Fam Pract 1989; 6: 19-22.

13. Forrest CB, Nutting PA, von Schrader S et al. Primary care physician specialty referral decision making: patient, physician, and health care system determinants. Med Decis Making 2006; 26: 76-85.

14. Akbari A, Mayhew A, Al-Alawi MA et al. Interventions to improve outpatient referrals from primary care to secondary care. Cochrane Database Syst Rev 2008; nr. 4: CD005471.

Mottatt 4.1. 2011, første revisjon innsendt 18.3. 2011, godkjent 26.3. 2011. Medisinsk redaktør Are Brean. 